\title{
Mulemba
}

Revista Angolana de Ciências Sociais

6 (11) | 2016

Políticas, direitos e práticas da sociedade e do Estado

\section{Assimetrias entre poder do Estado e direito de acesso à informação}

Asymmetries between the power of the State and right to access information

\section{Carmen Lúcia Batista}

\section{(2) OpenEdition \\ 1 Journals}

\section{Edição electrónica}

URL: http://journals.openedition.org/mulemba/1239

DOI: $10.4000 /$ mulemba.1239

ISSN: 2520-0305

\section{Editora}

Edições Pedago

\section{Edição impressa}

Data de publição: 1 maio 2016

Paginação: 13-23

ISSN: 2182-6471

\section{Refêrencia eletrónica}

Carmen Lúcia Batista, «Assimetrias entre poder do Estado e direito de acesso à informação»,

Mulemba [Online], 6 (11) | 2016, posto online no dia 13 outubro 2018, consultado o 28 janeiro 2021.

URL: http://journals.openedition.org/mulemba/1239; DOI: https://doi.org/10.4000/mulemba.1239

Tous droits réservés 


\title{
Assimetrias entre poder do Estado e direito de acesso à informação
}

\author{
Carmen Lúcia Batista*
}

\begin{abstract}
Resumo: A informação pública, apesar de estar directamente relacionada a diversas etapas da vida dos cidadãos esbarra na problemática das diferentes forças entre os actores em questão, ou seja, o Estado e a sociedade. A partir desse contexto, o objectivo deste trabalho é apresentar os «poderes» do Estado e os direitos da sociedade no que se refere ao acesso à informação pública. Como metodologia foi feita pesquisa documental em fontes especializadas nos temas em questão. Como conclusão, consideramos haver uma assimetria entre poderes do Estado e direitos da sociedade de acesso à informação pública.
\end{abstract}

Palavras-chave: Poder do Estado, informação pública, direito de acesso à informação pública, relação assimétrica.

\section{Introdução}

Desde as últimas décadas do século xx, há um movimento, nos âmbitos nacional e internacional, que está redefinindo a relação Estado-sociedade, envolvendo a questão da informação pública e visando a democratização do acesso da sociedade às diferentes instâncias do poder público. No entanto, a informação pública, apesar de estar directamente relacionada a diversas etapas da vida dos cidadãos (BATista 2010b) - já que várias das acções realizadas em uma sociedade são pautadas por determinações do Estado -, esbarra, dentre outras questões, na problemática das diferentes forças entre os actores em questão, ou seja, o Estado e a sociedade.

Especialista em ciências da informação. Directora do Núcleo de Documentação e Informação da Secretaria da Fazenda do Estado de São Paulo, República Federativa do Brasil. 
A partir desse contexto, o objectivo deste trabalho é apresentar os «poderes» do Estado (Braman 2006) e os direitos da sociedade (CANotilho 1992; 2003) evidenciando a força que os impulsiona. Como metodologia, foi feita pesquisa documental em fontes especializadas nos temas em questão.

\section{O Estado informacional e seu poder invisível}

Após a Segunda Guerra Mundial (1939-1945), conforme Braman (2006), as grandes corporações começaram a desenvolver-se e a atravessar fronteiras mais facilmente. Na década de 1970, segue a autora, as corporações multinacionais e transnacionais aprenderam a maximizar suas operações enquanto minimizam a extensão das restrições a que eram submetidas pelo Estado.

Nesse período, de acordo com a autora, o Estado começou a mudar sua forma. Desde então, o Estado tem reafirmado sua força de três modos:

1) Os governos têm aprendido a dominar o poder informacional que as corporações e outros actores não estatais têm usado com êxito em seus desafios geopolíticos;

2) Os Estados têm desenvolvido técnicas para ampliar o controle de entidades do sector privado, como as agências reguladoras;

3) Como uma empresa, o Estado está cada vez mais caracterizado como rede (networked), por causa da multiplicidade de formas que os governos têm utilizado para estreitar relações uns com os outros e com actores não estatais.

Esses três modos compõem o que Braman (2006: 36) denomina de «Estado informacional», caracterizado por interdependências múltiplas com outros estados e entidades não estatais de modos que requerem fortemente o uso de uma infraestrutura global de informação para criação, processo, fluxo e uso de informação. Os estados informacionais, segue a autora, usam o controle sobre a informação para produzir e reproduzir loci de poder, para moldar áreas de influências autónomas num ambiente de rede e para seus processos de disputa e de controle.

Para a autora, essa é a quarta fase de uma escala evolutiva do Estado. A primeira fase foi caracterizada pelo poder instrumental, 
entendido como a capacidade de modificar o comportamento humano mediante a manipulação do mundo material e a partir do emprego da força. Essa forma de exercício de poder se relaciona com o emprego de armas e meios militares, como os exércitos ou incentivos económicos.

A segunda fase é o poder estrutural, situação em que o Estado tem o poder de intervir sobre o comportamento dos indivíduos a partir da criação de instituições e regras. Leis, tratados, estruturas governamentais e o próprio processo político são maneiras de exercer esse tipo de poder.

A terceira fase trata-se do poder simbólico, caracterizado pela manipulação do comportamento humano mediante o domínio da imaginação e da percepção dos indivíduos, a partir da ideologização das ideias, das palavras e da imagem. A propaganda, o sistema educacional e as campanhas de mídia seriam exemplos desse tipo de intervenção.

A quarta fase, a do poder informacional, é marcada pelo uso de meta-tecnologias, que possibilitam a manipulação de bases de dados que dão suporte a outros tipos de poder. Envolve a forma como se organiza e manipula a informação e representa um «elo informacional» das diferentes formas de seu exercício pela organização e mineração de dados. Assim, conforme a autora, pela rede, para controle dos fluxos, o Estado penetra em diversas dimensões da existência humana, o que só a virtualidade pode possibilitar em tempo real, na convergência do político com a inovação tecnológica.

Assim, parece-nos que as duas primeiras fases do Estado operam no âmbito concreto, pois em ocasião de manifestação violenta pelas ruas podemos verificar a repressão pontual do Estado, que opera via poder de polícia (poder instrumental); da mesma forma, também podemos verificar que as regras criadas pelo Estado são «palpáveis» e instrumentais quando, por exemplo, recebemos uma multa de trânsito (poder estrutural). Já as duas últimas fases operam no âmbito do «invisível», conforme destaca Bobbio (2000; 2004) ao comentar o «poder invisível» do Estado, uma capacidade de ver sem ser visto. A acção subliminar do Estado em seus programas de governo (poder simbólico) não é visível com muita facilidade; assim como também não é facilmente percebida a capacidade do Estado em controlar os fluxos informacionais sobre a vida dos cidadãos (poder informacional). 
Nas duas primeiras fases, o Estado exerce, legitimamente, funções que cabem a ele desempenhar (DALLARI 2007); nas duas últimas, funções que não são propriamente «de Estado», talvez, por isso, não sejam tão visíveis assim. Não podemos deixar de notar que essas fases não são lineares e autoexcludentes, ou seja, uma não substitui a outra no tempo e no espaço, antes, ao contrário, são concomitantes.

Dentre vários aspectos possíveis de serem aprofundados a partir dessa classificação de Braman, a este trabalho interessam apenas as três últimas fases (poderes estrutural, simbólico e informacional). Vamos considerar como elas tangem a cidadania e as questões do direito de acesso à informação pública.

\section{Informação pública: uma questão de direito}

Em trabalho anterior, resultado de uma pesquisa de mestrado sobre acesso e apropriação social da informação produzida pelo Estado, tratamos do conceito de informação pública, no qual foram considerados os vários sentidos implícitos no termo público. Assim,

"[...] informação pública é um bem público, tangível ou intangível, com forma de expressão gráfica, sonora e/ou iconográfica, que consiste num patrimônio cultural de uso comum da sociedade e de propriedade das entidades/instituições públicas da administração centralizada, das autarquias e das fundações públicas. A informação pública pode ser produzida pela administração pública ou, simplesmente, estar em poder dela, sem o status de sigilo para que esteja disponível ao interesse público/coletivo da sociedade. Quando acessível à sociedade, a informação pública tem o poder de afetar elementos do ambiente, reconfigurando a estrutura social» (BATISTA 2010b: 40).

Essa concepção de informação pública refere-se à informação produzida pelo Estado, é a informação sobre o Estado, a qual também é de interesse público, conforme esclarecido em trabalho posterior (BAtista 2014). Contudo, embora o sentido do conceito informação pública seja mais amplo, a este trabalho interessa apenas a informação produzida pelo Estado, também denominada «informação estatal». Assim, a informação pública, em sua especificidade estatal, abrange três dimensões (BATISTA 2010a): 
- Dimensão comunicativa: a que anuncia dados estatísticos, esclarece procedimentos e comunica tramitações. Com informações dessa natureza, a administração pública divulga a taxa de mortalidade infantil, a expectativa de vida da população, a densidade demográfica das regiões, os pontos da cidade com maior índice de assalto, o valor venal dos veículos para o pagamento do imposto sobre propriedade de veículo automotor (IPVA), a contratação de empresas para pavimentar ruas, colectar o lixo, executar o transporte público, etc.

- Dimensão normativa: a que decide a vida das pessoas, em particular, e da sociedade e do país, como um todo, por meio de julgados de tribunais ou actos normativos (constituição, lei, decreto, resolução, etc.). Por intermédio de informações dessa natureza, o Estado decide: a) se um indivíduo terá sua liberdade cerceada, se é herdeiro de espólio, devedor de pensão alimentícia, obrigado a pagar um imposto ou isento dele, etc.; b) se a sociedade pode ter acesso à informação pública, pode participar das decisões públicas, etc.; c) se o país terá um sistema de governo representativo ou não, se terá uma forma de Estado mais, ou menos, democrática, etc.

- Dimensão comprobatória: a que permeia e intermedeia os principais eventos da vida de uma pessoa, por meio de documentos que comprovam direitos e obrigações. Desse modo, o Estado certifica o nascimento; o casamento e a habilidade para condução de veículos; atesta o óbito; reconhece o diploma; autoriza a abertura e o fechamento de empresa; permite o trânsito das pessoas entre países; atribui identidade civil, etc.

Assim, percebemos que o Estado permeia várias etapas da vida civil do cidadão e, em muitas delas, produz documentos que autorizam ou não o ir e vir, o fazer e não fazer, o ter e não ter, além de dar a conhecer ou não dar a conhecer. Essas dimensões estão alinhadas ao conceito de poder estrutural de Braman (2006), situação em que o Estado cria regras, como leis, tratados, etc. Elas se relacionam à necessidade pontual de informação concreta, ou seja, necessidade de um documento produzido pelo Estado. Elas não são fraccionadas, ao contrário, estão em relação entre si e têm como argumento o direito de acesso à informação.

No mesmo sentido, Lamizet (1999) considera que o direito representa uma institucionalização das práticas sociais, sendo a inscrição 
de uma lógica do exercício do poder que organiza a vida social e estrutura as relações entre os homens em virtude de decisões tomadas pelo poder político.

A posição de Lamizet (1999) em relação ao direito é similar à de Braman (2006) em relação à informação. Embora ambas as posições tratem de questões e avanços que são de benefício social e, por isso, relevantes, a formulação dos modos de direito relacionados à informação pública, principalmente no que se refere às diferenças entre liberdade de informação e de expressão, é resultado de uma longa luta por garantias individuais e colectivas que em todo o mundo mobilizou, e ainda mobiliza, organismos internacionais preocupados com o desenvolvimento do processo democrático. ${ }^{1}$

Já no século xviII, Kant (1724-1804) formulou uma noção do princípio de publicidade que serviu de fundamento filosófico, jurídico e moral para sua obra. De acordo com o autor, «são injustas todas as acções que se referem ao direito de outros homens, cujas máximas não se harmonizem com a publicidade» (KANT 2008: 46). O autor continua:

«[...] uma máxima que eu não posso manifestar em voz alta sem que, ao mesmo tempo, se frustre a minha própria intenção, que deve permanecer inteiramente secreta se quiser ser bem sucedida, e que posso confessar publicamente sem provocar de modo inevitável a oposição de todos contra o meu propósito, uma máxima assim só pode obter a necessária e universal reacção de todos contra mim, cognoscível a priori, pela injustiça com que a todos ameaça» (KANT 2008: 47, grifos do autor).

O filósofo pretendia conectar precisamente a justiça da norma, sua potencialidade de formulação pública e a capacidade de ser racionalmente aceita pelo público, conjecturas que compõem seu pensamento referente à moral.

Passados mais de dois séculos desde a formulação de Kant, vários países têm publicado normas que viabilizam o acesso à informação pública, aparente resultado das práticas sociais (LAMIZET 1999) das sociedades que clamam por transparência. No entanto, mesmo a lei

1 Em pesquisa anterior (BATISTA 2010b), foi descrito o histórico do direito de acesso à informação em âmbito nacional e internacional. 
sendo necessária, a noção de direito veiculada por ela ainda é insuficiente para atingirmos o ideal proposto por Kant.

Sobre esse aspecto, uma ampliação da noção de direito à informação é proposta por Canotilho (1992). Segundo este autor, o acesso à informação é um direito fundamental que abrange três níveis: o direito de informar, o de se informar e o de ser informado. Weichert (2006) explica o significado dessa tríade: o direito de informar tem sua origem histórica na liberdade de imprensa, porém, modernamente se irradia para toda e qualquer pessoa ou entidade, pública ou privada; o direito de se informar é o direito, individual ou colectivo, de busca de dados ou de documentos de interesse pessoal ou colectivo no Estado ou nos bancos de dados públicos; o direito de ser informado tem por conteúdo o recebimento de informações fidedignas do Estado sobre quaisquer factos de interesse público, bem como o pleno acesso à informação mantida em arquivos públicos, de interesse público ou particular.

Assim, o direito à informação deve ser entendido como mais abrangente que o de liberdade de imprensa (liberdade de informar) e diferente do direito à liberdade de expressão ou de informação, o qual pressupõe a liberdade de produzir informação e de emitir opinião.

Em obra posterior, Canotilho (2003: 514-516) amplia ainda mais a noção do direito de acesso à informação. Ao declarar que o segredo não é compatível com as liberdades e os direitos do homem porque representa ao cidadão a «digitalização dos direitos fundamentais», o autor propõe o direito à autodeterminação informativa, que significa a faculdade de o particular determinar e controlar a utilização dos seus dados pessoais. Canotilho (2003) ainda postula o direito ao arquivo aberto, que se traduz não apenas em acesso a documentos administrativos com conteúdo de interesse pessoal, mas também a um direito de saber, já sinalizado por Kant (2008), que possibilita acesso ao que acontece no âmbito dos esquemas políticos burocráticos. Enfim, também é proposto o direito a uma comunicação aberta entre as autoridades e os cidadãos.

Desse modo, para o homem comum usufruir de todas as nuances do direito de acesso à informação apresentadas por Canotilho (1992; 2003) estão implicadas várias problemáticas, como as da documentação e da organização da informação pública, só para citar algumas. A falta de organização da informação pode resultar em resposta negativa em relação à existência de documentos públicos. 
Esse facto desperta a atenção para uma questão: o direito de se informar pode ser negativamente substituído pelo direito de ser informado, pois a comunicação sobre a não existência do documento refere-se ao procedimento de prestação de contas, acto que também se configura em direito de ser informado, mas é «ser informado» sobre a ausência do que é procurado. Desse modo, para que o acesso físico à informação pública seja efectivo, a sociedade necessita tomar conhecimento de toda cadeia de produção da informação pública, ou seja, a génese, o fluxo e o armazenamento. É o direito de saber de que trata Canotilho (2003).

\section{Considerações finais}

Face à destacada essencialidade da informação pública na vida social e particular de cada cidadão, parece-nos que o Estado não actua em favor dos cidadãos se não proporcionar a eles o acesso à informação pública.

Ao compararmos os vários «poderes» do Estado (BRAman 2006) - alguns legítimos (poder instrumental e poder estrutural), outros nem tanto (poder simbólico e poder informacional) - com os diversos «direitos» da sociedade (CANOTILHO 1992; 2003) percebemos uma assimetria entre esses actores. Por um lado temos um Estado investido de força de actuação em vários âmbitos; por outro, uma sociedade que para ter direito a acessar informações sobre si própria perante um Estado empoderado tem que reivindicar, em seu melhor estado de organização, direitos perante esse mesmo Estado potente que regula a vida social das pessoas (poder informacional) e que também se autorregula. É como a mão que se desenha, conforme a obra do artista plástico holandês Escher.

Essa assimetria de forças é ainda mais presente em razão do «poder invisível» do Estado (Воввіо 2000; 2004). Nesse contexto, invisibilidade não é sinónimo de transparência, ao contrário, esconde práticas que não são conhecidas por todos. Quanto menos direito de acesso à informação pública a sociedade tiver, mais «invisível» o Estado se tornará e, consequentemente, maior será a assimetria entre esses dois actores. 


\section{Referências bibliográficas}

Batista C. L.

2010a, "As dimensões da informação pública: Transparência, acesso e comunicação", TransInformação (Campinas), vol. 22, n. ${ }^{\circ}$ 3, Setembro/ Dezembro, pp. 225-231. Disponível em <http:// periodicos.puc-campinas.edu.br/seer/index.php/transinfo/article/view/496>, acesso em Dezembro de 2015.

2010b, Informação pública: Entre o acesso e a apropriação social. Dissertação de Mestrado em Ciência da Informação. São Paulo, Escola de Comunicações e Artes, Universidade de São Paulo, 202f. Disponível em <http://www.teses.usp.br/teses/disponiveis/27/27151/tde-05112010-110124/pt-br.php>, acesso em Dezembro de 2015.

2014, Mediação e apropriação da informação pública: A educação fiscal. Tese de Doutoramento em Ciência da Informação. São Paulo, Escola de Comunicações e Artes, Universidade de São Paulo, 273f. Disponível em <http://www.teses.usp.br/teses/disponiveis/27/27151/tde-18052015-160609/pt-br.php>, acesso em Dezembro de 2015 .

BobBio N.

2000 (9. ${ }^{\mathrm{a}}$ edição), O futuro da democracia (Uma defesa das regras do jogo). Tradução de Marco Aurélio Nogueira. São Paulo, Paz e Terra.

BRAMAN S.

2006, Change of State: Information, policy and power. Cambridge, MIT Press.

1989, «Defining information: An approach for policymakers», Telecommunications Policy (Beverly Hills), vol. 13, n. $^{0}$ 1, pp. 233-242, Sage.

CAnotilho J. J. G.

2003 ( $7 \cdot^{\mathrm{a}}$ edição), Direito constitucional e a teoria da constituição. Coimbra, Almedina.

1992 ( $5 \cdot^{\text {a }}$ edição), Direito constitucional. Coimbra, Almedina.

DALLARI D. A.

2007 (27. ${ }^{\text {a }}$ edição), Elementos de teoria geral do Estado. São Paulo, Saraiva.

KANT I.

2008 [1795], A paz perpétua: Um projecto filosófico. Tradução de Artur Morão. Covilhã, LusoSofia Press [«Textos clássicos de filosofia»]. Disponível em <http://www.lusosofia.net/textos/kant_ immanuel_paz_perpetua.pdf $>$, acesso em 24 de Agosto de 2015. 
LAMIZET B.

1999, La mediation culturelle. Paris, L'Harmattan.

Weichert M. A.

2006, Dicionário de direitos humanos: informação (direito à). Disponível em <http://www.esmpu.gov.br/dicionario/tiki-index.php?page=Informa\%C3\%A7\%C3\%A3o>, acesso em 27 de Julho de 2015.

Recepção do manuscrito: 11/04/2016

Aceite para publicação: 25/05/2016

Title: Asymmetries between the power of the State and right to access information

\begin{abstract}
Although public information is directly related to the various stages of citizens' lives, it collides with different forces representing the relevant actors, that is, the State and society. From this context, the aim of this work is to present the "powers" of the State and the rights of society with regard to access to public information. The methodology is based on documentary analysis of specialized sources in the subjects under analysis. In conclusion, we consider that there is an asymmetry between the powers of the State and the rights of society in access to public information.
\end{abstract}

Keywords: Power of the State, public information, right of access to public information, asymmetric relationship.

\title{
Carmem Lúcia Batista
}

Doutora em Ciência da Informação pela Escola de Comunicações e Artes (ECA) da Universidade de São Paulo (USP), onde submeteu a tese de doutoramento intitulada Mediação e apropriação da informação pública: A educação fiscal (2014). Possui Mestrado em Ciências da Informação (ECA-USP), tendo submetido a dissertação intitulada Informação pública: Entre o acesso e a apropriação social (2010), e graduação em Biblioteconomia (ECA-USP) e em Letras (Português/Francês) pela Faculdade de Filosofia, Letras e Ciências Humanas da Universidade de São Paulo (FFlch-USP). É Directora do Núcleo de Documentação e Informação da Secretaria da Fazenda do Estado de São Paulo (República Federativa do Brasil). As suas principais áreas de actuação são as Ciências Sociais Aplicadas na área da Ciência da Informação, Biblioteconomia, Linguística, Letras e Artes.

Além dos materiais já citados, publicou ainda, ou apresentou comunicação em eventos, tais como: «Mediação e apropriação: Questões do direito de acesso à informação», in Maria Aparecida Moura (org.), A construção 
social do acesso público à informação no Brasil: Contexto, historicidade e repercussões (Belo Horizonte, UFMG, 2014, pp. 137-152); «El acesso a la información pública y la política del mercado internacional», in Anais do Simposio Latinoamericano sobre o acesso a la información gubernamental (Ciudad de Mexico, 2014); "Informação pública: Controle, segredo e direito de acesso", in Texto (UFRGs, on line, vol. 26, 2012, pp. 204-222); "As relações entre informação e comunicação no programa Nota Fiscal Paulista», in Anais do XIII Enancib (Rio de Janeiro, 2012); «Informação pública: Uma questão de acesso, de direito e de apropriação social», in Tendências da Pesquisa Brasileira em Ciências da Informação (vol. 4, 2011, p. 20); «Informação pública. Uma questão de acesso, de direito e de apropriação social», in Anais do XII Enancib (Brasília, DF, 2011); «As dimensões da informação pública: Transparência, acesso e comunicação», TransInformação JCR (vol. 22, 2010, pp. 225-231); «A modernização do Núcleo de Documentação e Informação da Secretaria de Fazenda», in Anais do XXII Painel de Biblioteconomia de Santa Catarina (Florianópolis, 2004).

[e-mail: carlubatista@gmail.com]. 